\title{
Nikol Dziub, Voyages en Andalousie au XIX siècle
}

\section{Lise Sabourin}

\section{OpenEdition \\ Journals}

\section{Édition électronique}

URL : https://journals.openedition.org/studifrancesi/21316

DOI : 10.4000/studifrancesi.21316

ISSN : 2421-5856

\section{Éditeur}

Rosenberg \& Sellier

\section{Édition imprimée}

Date de publication : 1 décembre 2019

Pagination : 577

ISSN : 0039-2944

\section{Référence électronique}

Lise Sabourin, "Nikol Dziub, Voyages en Andalousie au xIx siècle », Studi Francesi [En ligne], 189 (LXIII I III) | 2019, mis en ligne le 01 mars 2020, consulté le 12 novembre 2021. URL : http://

journals.openedition.org/studifrancesi/21316; DOI : https://doi.org/10.4000/studifrancesi.21316

Ce document a été généré automatiquement le 12 novembre 2021.

\section{(c) (†)}

Studi Francesi è distribuita con Licenza Creative Commons Attribuzione - Non commerciale - Non opere derivate 4.0 Internazionale. 


\title{
Nikol Dziub, Voyages en Andalousie au XIX siècle
}

\author{
Lise Sabourin
}

\section{RÉFÉRENCE}

Nikol Dziub, Voyages en Andalousie au XIX siècle, Genève, Droz, 2018, 441 pp.

1 L'Andalousie fait partie de ces Édens perdus que les écrivains-voyageurs du XIXe siècle ont placés parmi leurs prototypes de locus amoenus. Nikol Dziub se livre dans cet ouvrage à une réflexion sur la façon dont ils ont affronté le mal des ruines, l'impact de la presse à grand tirage, la concurrence de la photographie pour fuir l'uniformisation du monde et de la littérature. Ce livre sur les Voyages en Andalousie au XIX siècle répartit en huit chapitres les apports des nombreux auteurs qui s'y sont livrés, de Laborde en 1806 à De Amicis en 1873.

2 Remontant d'Homère à Swinburne, Dziub montre dans le premier chapitre (pp. 23-57) comment on est passé des clichés hérités de l'antiquité au voyage d'antiquaire du Grand Tour initié par les Anglais. Puis le chapitre II (pp.59-94), à travers l'Itinéraire d'Alexandre de Laborde, l'Itinéraire de Paris à Jérusalem et le Dernier Abencérage de Chateaubriand et le Voyage pittoresque en Espagne du baron Taylor (1823), étudie les enjeux patrimoniaux et politiques ainsi déployés face à l'apport de la lithographie qui nécessite de cerner par complémentarité l'esprit des lieux avec sensibilité et par la transcription des légendes. Place ensuite, dans le chapitre III (pp. 95-150), à l'américain Washington Irving au souci plus étiologique: il vient chercher à comprendre l'origine des Espagnols qui ont assuré la colonisation du Nouveau Monde, notamment en sondant les mystères de l'Alhambra. Le chapitre IV (pp.151-230) se concentre sur Gautier, avec toute sa fantaisie et sa connaissance de la peinture hispanique, particulièrement de Goya, pour mettre en scène sa vision de l'Andalousie, y compris par des poèmes, face au feuilleton journalistique. Le chapitre $V$ (pp. 231-268) laisse la parole à Dumas père, qui mesure l'étendue de sa gloire à l'accueil qui lui est réservé, 
notamment par ses lectrices, à travers son Gentilhomme d'Andalousie, Dom Alejandro. Mais aussi désormais les méthodes modernes (guides de voyages Murray, chemins de fer, Exposition Universelle, photographies de voyages) tiennent leur place dans la diffusion des connaissances des pays étrangers (chapitre VI, pp. 269-318). Aussi les regards périphériques du russe Botkine, du danois Andersen (chapitre VII, pp. 319-360) et les relations illustrées par Doré du Tour du monde et de l'italien De Amicis (chapitre VIII, pp. 361-403) posent-ils les questions existentielles et communautaires qui s'attachent à ces périples qui n'ont plus pour but comme Ulysse de rentrer, plein d'usage et raison, au pays.

3 L'ouvrage, encadré par une introduction (pp. 7-22) posant bien la dynamique et une conclusion nette (pp. 405-410), muni de bibliographie, index et illustrations, synthétise de manière fort intéressante cet «Orient» du Sud que représente l'Andalousie dans la construction mentale de l'imaginaire moderne. 